\title{
Enhanced Assessment of the Air Transportation System
}

\author{
M. Weiss ${ }^{1}$, T. Gmelin ${ }^{2}$, X. Sun ${ }^{3}$, N. Dzikus ${ }^{4}$ \\ DLR - Air Transportation Systems, 21079 Hamburg, Germany
}

This paper recommends an approach on how to assess the Air Transportation System (ATS) that draws on the results in [1], and considers the 3 pillars of sustainability: economy, ecology and society. A framework has been developed to conduct sustainability studies of ATS and its sub elements separately. The framework shows the combination of Life Cycle Assessment (LCA), Life Cycle Cost Assessment (LCC) and Social Life Cycle Assessment (SLCA). The final results of the inventory analysis will be aggregated in a single value, expressed as Socio-Eco-Efficiency Index (SEEindex). This paper does not present the inventory calculations itself, but contains a proposed description of synthesis of the inventory results using Multiple Criteria Decision Aid (MCDA) methods. Additionally a reduced structure of the ATS will be proposed, which includes the most important stakeholders. To demonstrate the proposed approach, it is applied to two new low noise aircraft configurations.

\begin{tabular}{|c|c|c|}
\hline & & Nomenclature \\
\hline $\mathrm{A}^{+/-}$ & $=$ & Positive/ negative virtual product alternatives \\
\hline$A_{i}$ & $=$ & Product alternatives \\
\hline ANSP & $=$ & Air Navigation Service Provider \\
\hline ATS & $=$ & Air Transportation System \\
\hline $\mathrm{C}_{\mathrm{i}}$ & $=$ & Cost inventory results $[\$],[€]$ \\
\hline$e_{i}$ & $=$ & Ecology inventory results [different units: e.g. $\mathrm{dB}, \mathrm{kg}, \mathrm{m}^{2}$ ] \\
\hline $\mathrm{D}_{\mathrm{i}}$ & $=$ & Decision matrices \\
\hline $\mathrm{d}$ & $=$ & TOPSIS indices [1] \\
\hline ISO & $=$ & International Standard Organization \\
\hline KPA & $=$ & Key Performance Area \\
\hline LCA & $=$ & Life Cycle Assessment \\
\hline LCC & $=$ & Life Cycle Cost \\
\hline LCSA & $=$ & Life Cycle Sustainability Assessment \\
\hline LCIA & $=$ & Life Cycle Impact Assessment \\
\hline MCDA & $=$ & Multiple Criteria Decision Aid \\
\hline$r_{i}$ & $=$ & Normalization vectors [1] \\
\hline RMP & $=$ & Rear Mounted Propulsion Aircraft \\
\hline $\mathrm{S}_{\mathrm{i}}$ & $=$ & Social inventory result [different units: e.g. employed people [1], income [\$]] \\
\hline SEEindex & $=$ & Social-Eco-Efficiency Index \\
\hline SEElab & $=$ & Social-Eco-Efficiency laboratory \\
\hline TOPSIS & $=$ & Technique for Order Preference by Similarity to Ideal Solution \\
\hline UNEP & $=$ & United Nations Environment Programme \\
\hline VIP & $=$ & Virtual Integration Platform \\
\hline $\mathrm{w}_{\mathrm{i}}$ & $=$ & Weighting vectors \\
\hline $\mathrm{z}^{+/-}$ & $=$ & Positive/ negative relative closeness between virtual and real product alternatives \\
\hline
\end{tabular}

\footnotetext{
${ }^{1}$ Research scientist, DLR, Air Transportation System, Blohmstrasse 18, 21079 Hamburg (Marco.Weiss@DLR.de)

${ }^{2}$ Research associate, DLR, Air Transportation System, Blohmstrasse 18, 21079 Hamburg

${ }^{3}$ Research associate, DLR, Air Transportation System, Blohmstrasse 18, 21079 Hamburg

${ }^{4}$ Research associate, DLR, Air Transportation System, Blohmstrasse 18. 21079 Hamburg
} 


\section{Introduction}

$\mathrm{T}$ he Air Transportation System (ATS) is a complex system. The evaluation of its sustainability is a complicated task. Sustainability is described here by the combination of economical, ecological and social performance indicators, which should be optimized equally. Recently, 'Sustainability' became known as a term related to global development, defined in the United Nations Environment Programme (UNEP) Brudtland report [20]:

\section{Sustainable development is development that meets the \\ needs of present without compromising the ability of \\ future generations to meet their own needs.}

Currently, the overall assessment and optimization of products is mainly driven by improvements of its economic benefit. This is well established and is conducted especially in the industrial sector. The increase of the product value is the paramount target function for each stakeholder participating in the ATS. It has to be mentioned that 'product' refers to both goods, e. g. an aircraft, and services, provided to the aviation community e.g. by airlines, airports or the ANSP. But in the recent decades public interest in reducing environmental life cycle impact of products has grown continuously - as a result the demand for developing sustainable products has increased equivalently. Thus, the introduction of life cycle assessment in the evaluation and optimization process for new or redefined products and systems rose significantly. Additionally, in the last years the scope of inventory has been being extended to social indicators. Here, an application is introduced which allows the assessment not only of environmental impact and costs but also of the societal impacts of products and processes. The aim is to quantify the performance of the three dimensions of sustainability with one integrated tool in order to direct - and measure - sustainable development in the industrial or research sector. It enables and supports potential valuators within the decision process in product development and improvements, strategic planning, policy making or marketing. These applications are directly linked to the LCA guideline ISO 14040 [17], describing the only internationally standardized environmental assessment method. The ISO 14040 standards typically does not address the economic or social aspects of a product, but the life cycle approach and methodologies (overall framework) defined in this international standard could be applied to these other aspects too. At this point the international acknowledged UNEP/SETAC publication "Guidelines for Social Life Cycle Assessment of Products" [6] has to be highlighted. The latest developments indicate the following formulation for Life Cycle Sustainability Assessment (LCSA), described in Kloepffer [9] and improved into its current form including editorial hints of Finkbeiner [13]:

$$
L C S A=L C A+L C C+S L C A
$$

$$
\begin{aligned}
& \text { with LCSA = Life Cycle Sustainability Assessment } \\
& \text { LCA = Environmental Life Cycle Assessment } \\
& \text { LCC = LCA-type Life Cycle Costing } \\
& \text { SLCA = Social Life Cycle Assessment }
\end{aligned}
$$

This scheme (1) suggests a separate execution of assessment for each dimension of sustainability, whereas the system boundaries of the three assessments should be consistent (ideally identical). In order to avoid double counting, external costs, which may occur in the future due to aviation environmental impacts, should not be monetized. Environmental impacts are dealt with as part of LCA in physical - as opposed to monetary - terms. Costs occurring in the future, e.g. due to climate change or land demand are difficult, even impossible to estimate. External costs that are expected in the near future or that are already internalized comprise real money flows, such as environmental landing charges or taxes and must be included in the LCC. Nevertheless, these internalized costs might not reflect the real environmental impacts; hence they have to be accounted separately in the LCA.

In accordance with Kloepfer [9] and Finkbeiner [13], formula (1) can be rearranged by introducing the ecoefficiency term (3), appeared for the first time in 1990 [10]: 


$$
\text { with } \quad E E=\frac{\sum_{1}^{n} \text { desired Output }+ \text { postive external Effects }}{\sum_{1}^{n} \text { ecology damage }}
$$

Several recently developed LCSA methods implement the SLCA method in eco-efficiency analysis. For example, Saling et. al [19] extended the BASF eco-efficiency analysis by adding a social component, transferring the two-dimensional eco-efficiency portfolio to a three dimensional one; the environment is called SEEbalance ${ }^{\circledR}$. The idea behind this approach has inspired the development of the ATS assessment approach presented in this paper. The fundamental architecture of the LCSA approach for measuring the air transportation systems' performance and impacts is described in Figure 1. After goal and scope definition (1st step), for each assessment the life cycle inventory analysis (2nd step) is substantial part for all three dimensions. Therein the product's 'life cycle' is commonly subdivided into 4 phases (Figure 1).

\section{Procedure of synthesis and decision aid}

The principal assessment procedure is illustrated in Figure 1. The broadest analysis scope requires the ecological, economical and social inventory for each life stage. Depending on the goal and scope settings, suitable indicators and impact categories (decision criteria) have to be chosen, exemplarily shown for the ecological performance area. The highest aggregated result is achieved by consolidating each criterion to one value, here expressed as Socio-EcoEfficiency index (SEEindex). Its calculation requires normalizing all indicators in order to obtain a compatible dimension. Among others, the normalization method depends on the data available and the question to be answered. Each criterion will be normalized to a reference system by dividing it by a selected reference value. In accordance with the ISO 14040 [17] some examples of reference values are

- the total inputs and outputs for a given area that may be global, regional, national or local (e.g. the national GDP or $\mathrm{CO} 2$ emissions),

- the total inputs and outputs for a given area on per capita basis or similar measurement, and

- inputs and outputs in a baseline scenario, such as a given alternative product system (e.g. an existing aircraft or airport)

The global system may be considered as the most significant reference system. However, for normalization from a scientific point of view, stakeholders are often interested in reference definitions on a lower system level, because these provide a more direct link to the stakeholder's goals.

In the final step of the aggregation the relative importance of criteria need to be determined. Thus, a weighting procedure has to be applied. The relative significance of the different impact categories is defined by their weighting factors. The use of weighting factors often raises discussions about whether they are "scientifically correct" or not and whether the factors are representative 


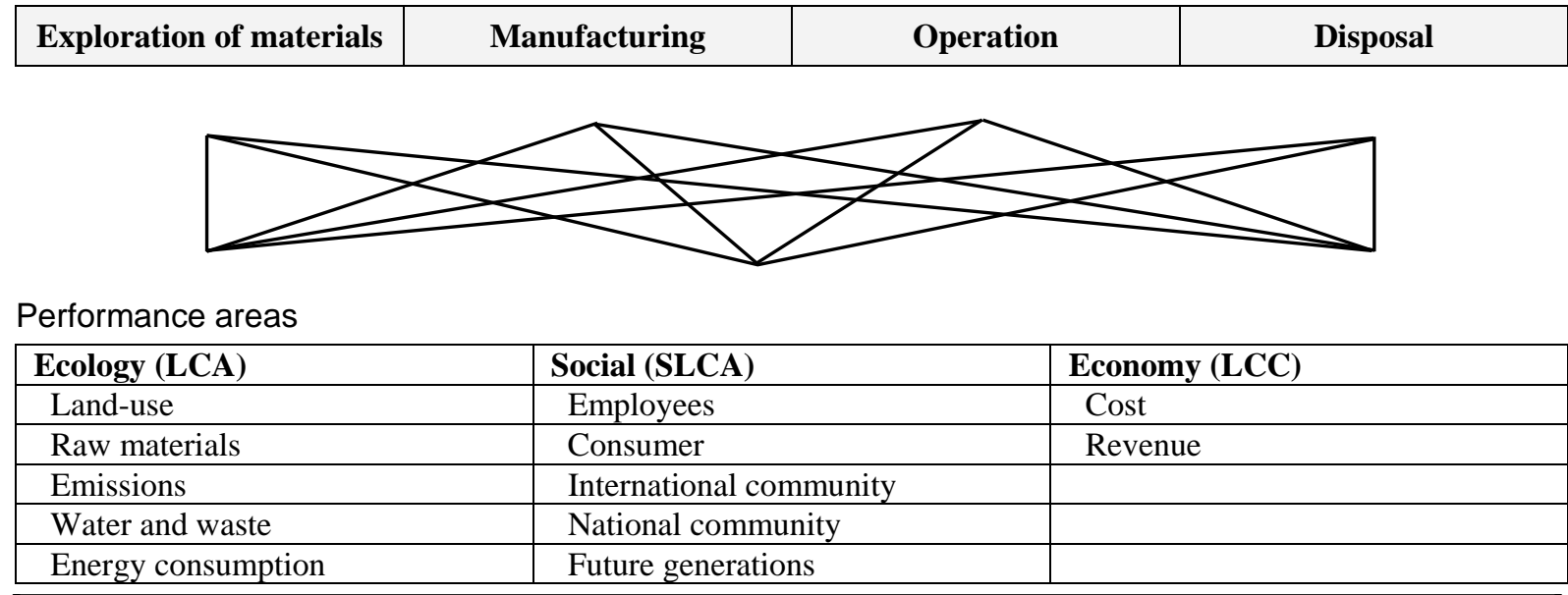

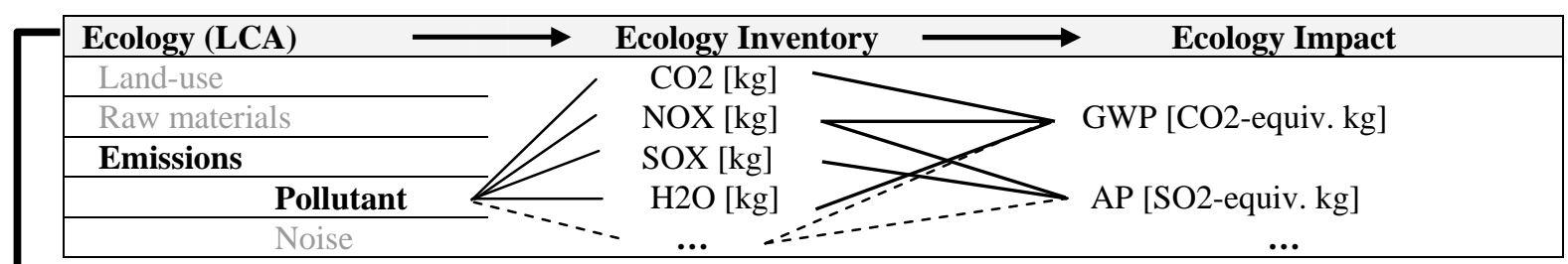

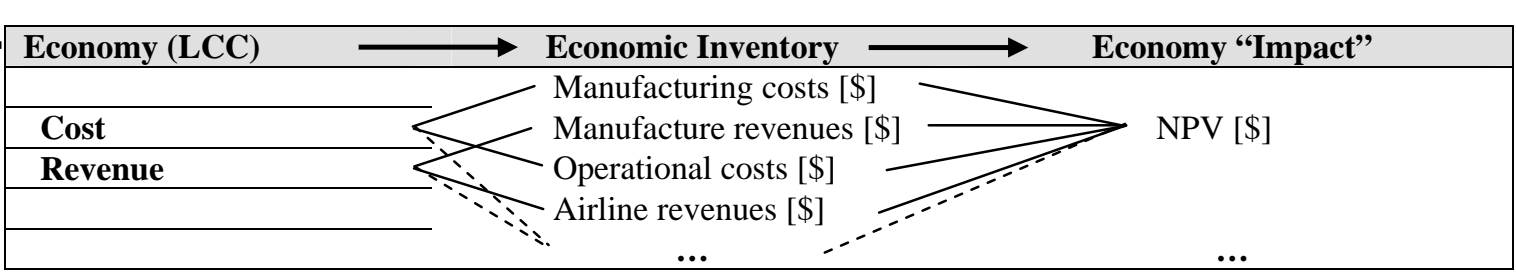

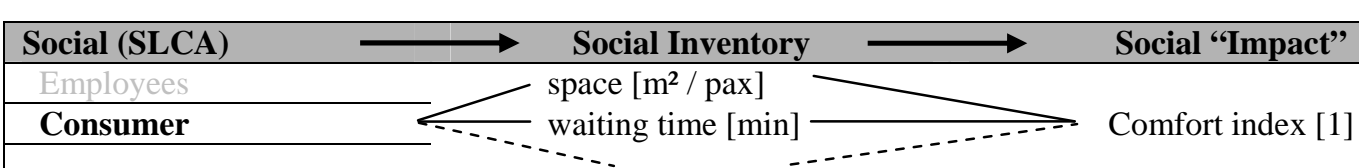

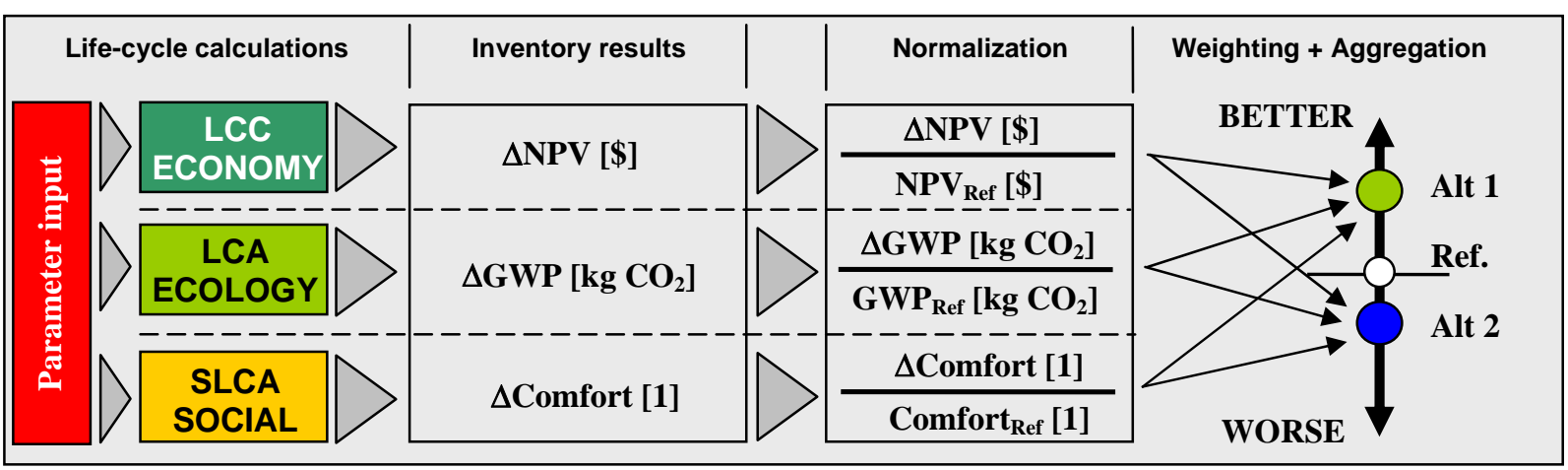

Figure 1: General assessment procedure (using example criteria)

4

American Institute of Aeronautics and Astronautics 
or not. Coping with this situation, the ISO 14044 (2006) [18] standard recommends: “[...] it may be desirable to use several different weighting factors and weighting methods, and to conduct sensitivity analysis to assess the consequences on the LCIA results of different value-choices and weighting methods." There are several different operational methods of weighting, which may lead to very different results. But this is all the more reason to apply diverse weighting techniques, except for having essential knowledge about the relative impact of each criterion. Fundamentally, one can distinguish between 'monetary' and ‘non-monetary valuation' methods as listed in Table 1 [14]: The distance-to-target (economic: cost-to-reach-target) principle is a common approach in LCIA. There, the weights are derived from the distance between the current level of the criteria and a future target value (for a detailed description, see Weiss et al. [3]). As described in Seppälä et al. [11] the method ranks an impact as more important the further away society is from achieving the desired standard for the criteria. However, the arguments for setting the targets may vary between countries and may be politically rather than scientifically based. Political targets are often agreed upon an arbitrary fashion. Shortly explained, the weight of impact category is calculated by dividing the distance-to-target factor by the target level. The total impact caused by an ATS element can be computed with (4). For calculation of environmental criteria, a generic example is given in Table 2. Within the temporal scope (e.g. a design optimization or product refinement over the life cycle) a regular 'distance'-review (in Table 2 stated as midterm review) should be applied with the intention of realigning the priorities. The simple linear approach presented here has some disadvantages because the impact of the categories will not be reflected adequately: It is based on the assumption that all targets are equally important. Hence, to capture the non-linear effects (e.g.: noise impacts), the distanceto-target weighting process can be enhanced by using damage functions, introduced and explained in Seppälä et al. [11].

$$
I(E)=\sum_{j=1}^{m} \frac{L_{j}^{N}}{\underbrace{L_{j}^{T}}_{\text {weight factor }} \cdot \frac{1}{L_{j}^{T}}} \cdot i_{j}(E) \cdot \underbrace{\frac{1}{N_{j}}}_{\text {Normalization }}
$$

where

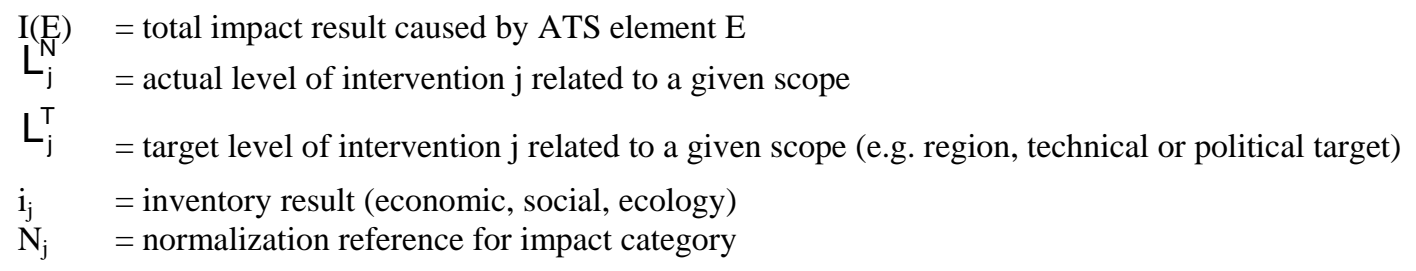

Table 2 Distance-to-target weighting with midterm review (generic example)

\begin{tabular}{|c|c|c|c|c|c|c|c|}
\hline ATS element & $\mathrm{T}_{0}$ & - & \multicolumn{3}{|c|}{$\mathrm{T}+\Delta \mathrm{T}$ (end term perspective) } & \multicolumn{2}{|c|}{$\left.\mathrm{T}+\Delta \mathrm{t}^{* *}\right)$ (midterm review) } \\
\hline & current & $\Delta$ & target $*$ ) & \multicolumn{2}{|c|}{ weight $\mathrm{w}$} & actual at $\Delta \mathrm{t}$ & weight w \\
\hline GWP [kg CO -equiv.] & 2,5E9 & $40 \%$ & $1,5 \mathrm{E} 9$ & $\rightarrow 1,7$ & $20,7 \%$ & $2,2 \mathrm{E} 9$ & $24,7 \%$ \\
\hline AP [kg SO -equiv.] & 3,4E7 & $9 \%$ & $3,1 \mathrm{E} 7$ & $\rightarrow 1,1$ & $13,4 \%$ & 3,4E7 & $18,4 \%$ \\
\hline Land-use $\left[\mathrm{km}^{2}\right]$ & 800 & $31 \%$ & 550 & $\rightarrow 1,5$ & $18,3 \%$ & 600 & $18,3 \%$ \\
\hline People affected [1] & 57800 & $63 \%$ & 21000 & $\rightarrow 2,7$ & $32,9 \%$ & 25000 & $20,0 \%$ \\
\hline Aircraft noise [EPNdB] & 85 & $18 \%$ & 70 & $\rightarrow 1,2$ & $14,7 \%$ & 78 & $18,6 \%$ \\
\hline \multicolumn{5}{|c|}{ *) set by stakeholders } & $100 \%$ & $* *)$ e.g.: $\Delta \mathrm{t}<0.5 \Delta \mathrm{T}$ & $100 \%$ \\
\hline
\end{tabular}

Monetary valuation methods are often used as a general term for all methods which have an economic measure as the unit for weighting factors. Based on Finnveden et al. [15], a distinction can be made between methods that are based on willingness-to-pay (or willingness-to-accept) - measuring an economic value (e.g. prevention or abatement costs) - and methods that are not based on willingness-to-pay. More detailed descriptions are stated in [15] and Ahlroth et al. [14]. Panel methods have in common that weighting factors are derived by a group of people by data acquisition. The group is asked about their values through the methodology of questionnaires, interviews or group discussions consisting of experts, stakeholders or citizens. The panel procedure can differ by a one-round or multi- 


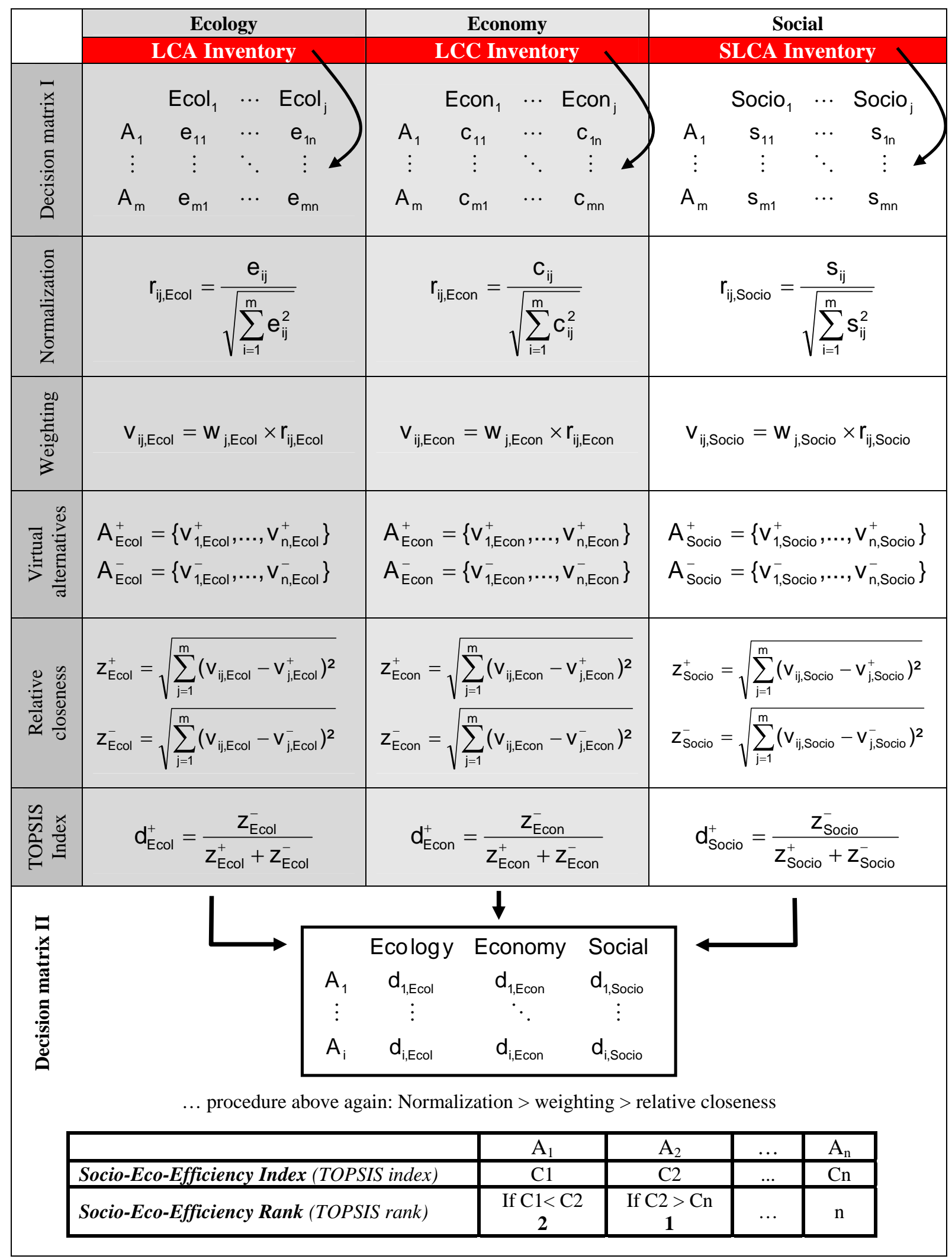

Figure 2: Mathematical description of assessment procedure with MCDA (TOPSIS) 
round procedure and with feedback (Delphi). Responses can differ by ranks, ratings, pair wise comparison or ranges etc. and to what extend background information is provided.

In this study the complete synthesis is conducted by a 4-fold MCDA process; executed for the economical, environmental and societal column and finally for aggregating the results to a single number (Socio-Eco-Efficiency-Index), described synoptically in Figure 2. MCDA is a process that allows making decisions in the presence of multiple, potentially conflicting criteria. There are a variety of existing MCDA methods, thus the selection of the most appropriate methods is critical. The use of inappropriate methods is often the cause of misleading design decisions. An intelligent knowledge-based system is developed, consisting of a MCDA library storing the widely used decision making methods and a knowledge base providing the information required for the method selection process (see Sun et al. [2]). An Appropriateness Index (AI) is proposed to evaluate the methods and identify the most suitable one. In our case, TOPSIS (Technique for Order Preference by Similarity to Ideal Solution) has been recommended as the most fitting MCDA method to be applied. The first decision matrices (I) include the inventory results of each criterion for $n$ alternatives. Weighting and normalization can be applied as described above. The resulted TOPSIS-Indices or partitioned as Ecology-Index, Economy-Index and Society-Index for each alternative are merged to the Socio-Eco-Efficiency-Index by using TOPSIS again. The alternative with the highest index might be the solution with the highest reachable sustainability compared to the other evaluated options.

At this point it has to be differentiated between a post- and an in-loop assessment. In the post-assessment, the alternatives have already been designed and even introduced in the system being evaluated. In the in-loop assessment, the alternatives can be redesigned for optimizing their sustainability. What approach to choose depends on the question whether either the alternatives (e.g. aircraft, airports, airspaces or its sub elements such as an airport terminal or runway system) have to be optimized in respect of its economic, environmental or social performance only or in all three sustainable dimensions. Additionally, if one merely wants to improve and compare the technical behavior of a product without being interested in its overall sustainable outcome, the procedure described in Figure 1 can be stopped after the inventory calculations (e.g. airfield capacity or check-in time). Nevertheless, MCDA can be applied for supporting the evaluators. Thus, the process described above (Figure 1 and Figure 2)

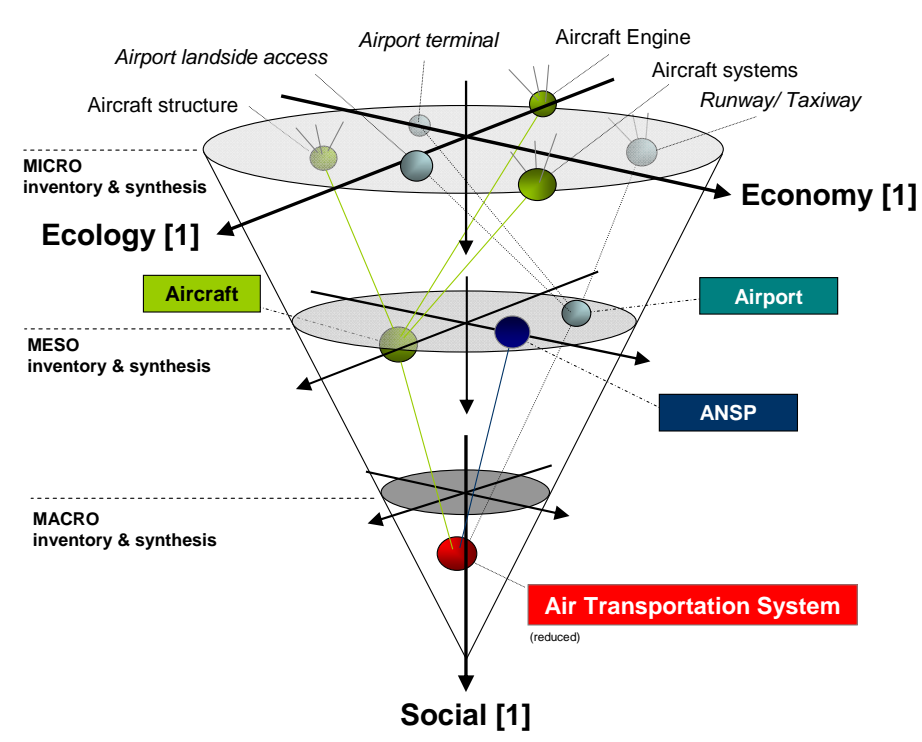

Figure 3: Stages at ATS SEE-Assessment

can be embedded in the optimization strategy at different ATS design points (Figure 3): In the microscopic level this means the improvement of product (airport, aircraft,...) sub elements, in the meso-level the synthesized primary ATS elements and in the macro level the integrated air transportation system.

\section{SEEtrade and assessment of ATS by an example}

In this chapter a new low noise aircraft configuration is taken as a simplified example to show how the assessment described in chapter 1 and 2 can be used, the reference aircraft is similar to a Boeing B737 or Airbus A320 (Figure 4). This is also introduced in Gollnick et al. [16] as VIP 1 reference case. First, the inventory calculations define the system boundaries and are necessary to select the performance indicators. Thus a primary ATS structure has been defined, to obtain a consistent definition. The recommended structure of the ATS is subdivided into 4 stakeholders (Table 3): Airport operator, manufacturer, airline operator and ANSP. For each of these stakeholders subcategories have been indentified to detail the system description. A broad inventory of the ATS has to cover all of these elements concerning environmental, economical and social implications of construction and operation. Depending on the assessment task or level of detail, the number of elements can be reduced to focus on a single system 
component. For example, if the introduction of a new runway lighting system should be investigated, then only the 'runway system' will be considered The boundaries should be extended to the 'aircraft operation at airport' if this new lighting system also influences the airfields' capacity or concerns the aircraft operator. In the case of evaluating a new aircraft, the scope of investigation is much broader. Besides its impacts on airport operations, maybe also on its infrastructure due to necessary extensions, its effects on operator, manufacturer and ANSP have to be accounted. The inventory scope is strongly focused on the airline and airport perspective. The new configurations are referenced to a current short/ medium range aircraft, the highest potential candidate to be substituted.

Table 3: 4-stakeholder-model

\begin{tabular}{|c|c|}
\hline $\begin{array}{l}\text { I) Airport operator } \\
\text { 1. Infrastructure construction and operation } \\
\text { - } \quad \text { Runway system } \\
\text { - } \quad \text { Taxiway system } \\
\text { - } \quad \text { Teron system } \\
\text { - } \quad \text { Tank farm } \\
\text { - } \quad \text { Landside access } \\
\text { 2. Aircraft operation at Airport } \\
\text { - } \quad \text { Ground handling } \\
\text { - } \quad \text { Aircraft ground operations } \\
\text { - } \quad \text { Aircraft CTR/ TMA operation }\end{array}$ & $\begin{array}{l}\text { II) Manufacturer } \\
\text { 1. Plant construction and operation } \\
\text { - } \quad \text { Production facilities } \\
\text { - } \quad \text { Research and test facilities } \\
\text { - } \quad \text { Office facilities } \\
\text { - } \quad \text { Logistic infrastructure } \\
\text { - } \quad \text { Power and cogeneration plants }\end{array}$ \\
\hline $\begin{array}{l}\text { III) ANSP } \\
\text { 1. Infrastructure construction and operation } \\
\text { - } \quad \text { Administrative buildings } \\
\text { - } \quad \text { Operative buildings } \\
\text { - } \quad \text { Airport navigation systems } \\
\text { - } \quad \text { En-route navigation systems } \\
\text { - Training facilities } \\
\text { 2. Aircraft operation } \\
\text { - Apron / Ground } \\
\text { - Tower (Runway/ CTR) } \\
\text { - Radar (TMA/ En-route) }\end{array}$ & $\begin{array}{l}\text { IV) Aircraft operator (e. g. Airline) } \\
\text { 1. Infrastructure construction and operation } \\
\text { - } \quad \text { Administrative buildings } \\
\text { - } \quad \text { Maintenance facilities } \\
\text { - } \quad \text { Cargo facilities } \\
\text { • } \quad \text { Terminal facilities } \\
\text { 2. Aircraft } \\
\text { - } \quad \text { Aircraft operation } \\
\text { - } \quad \text { Aircraft maintenance }\end{array}$ \\
\hline
\end{tabular}

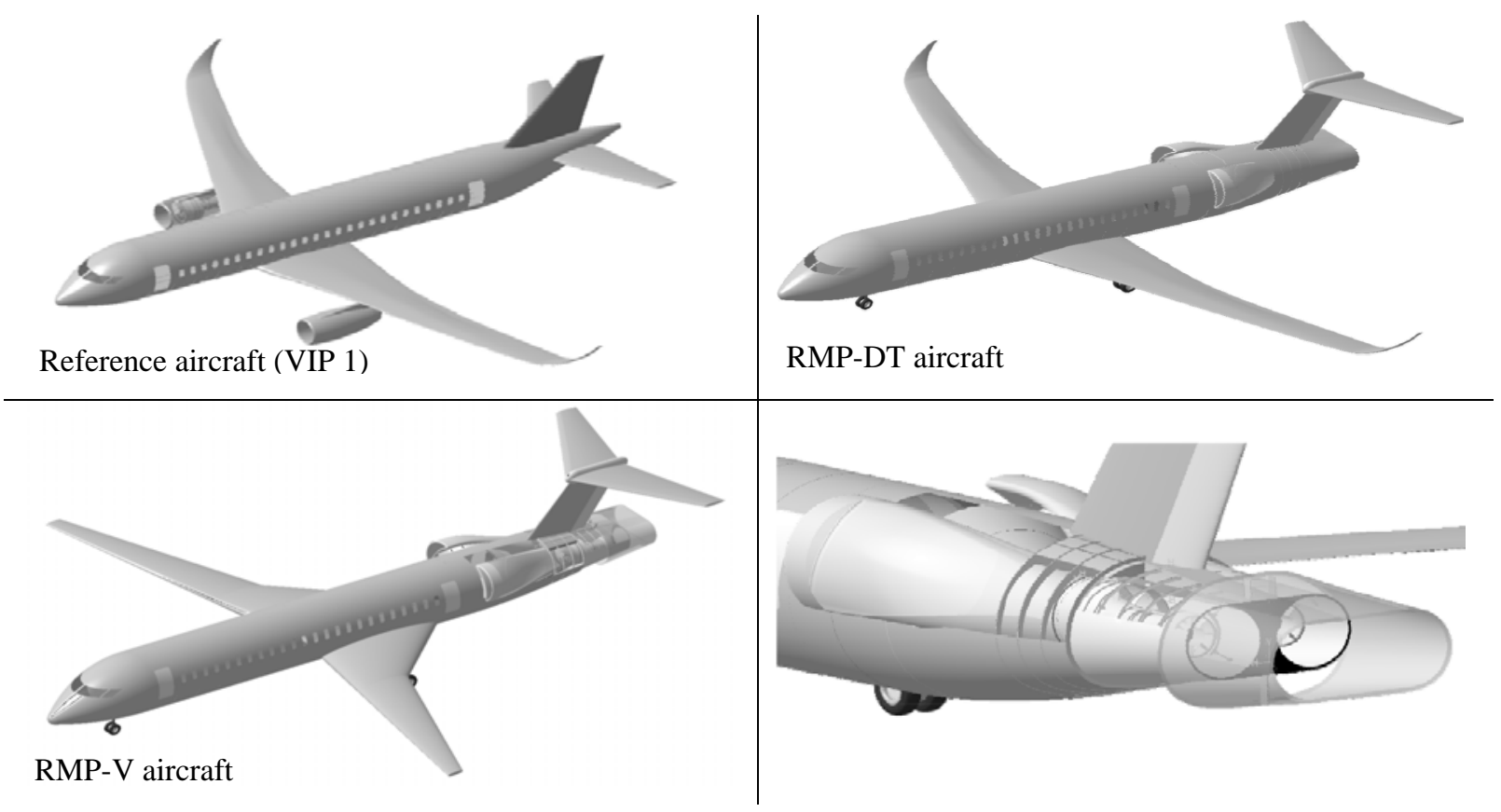

Figure 4: Reference aircraft (top left); RMP aircraft (top right and bottom left) and rear ejector system [5] 
Table 4: Technical performance of reference aircraft and RMP configurations [5]

\begin{tabular}{|r|c|c|c|c|c|}
\hline Inventory indicator & Reference & $\boldsymbol{R M P}-\mathbf{D T}$ & $\boldsymbol{\Delta}$ & $\boldsymbol{R} \boldsymbol{M P}-\boldsymbol{V}$ & $\boldsymbol{\Delta}$ \\
\hline Pax & 150 & 150 & $0,0 \%$ & 150 & $0,0 \%$ \\
\hline MTOW [t] & 73,5 & 76,2 & $+3,7 \%$ & 76,9 & $+4,6 \%$ \\
\hline OEW [t] & 42,3 & 43,9 & $+3,8 \%$ & 44,1 & $+4,3 \%$ \\
\hline Max payload [t] & 18,5 & 18,5 & $0,0 \%$ & 18,5 & $0,0 \%$ \\
\hline R at max payload (DP) [nm] & 1806 & 1807 & $0,0 \%$ & 1811 & $0,0 \%$ \\
\hline payload at 2500 nm [t] & 14,9 & 14,9 & $0,0 \%$ & 14,7 & $-1,4 \%$ \\
\hline Fuel demand at DP [t] & 10,3 & 11,2 & $+8,7 \%$ & 11,6 & $+12,6 \%$ \\
\hline Ferry range [nm] & 3463 & 3359 & $-2,4 \%$ & 3263 & $-5,2 \%$ \\
\hline Climb rate [m/s] & $\varnothing 21,0$ & $\varnothing 21,0$ & $-1,9 \%$ & $\varnothing 21,9$ & $+2,3 \%$ \\
\hline Climb rate in FL350 [m/s] & $2,0(\mathrm{M} 0,73)$ & $2,0(\mathrm{M} 0,73)$ & $0,0 \%$ & $2,0(\mathrm{M} 0,73)$ & $0,0 \%$ \\
\hline Climb time, FL350 [min] & $1,4(\mathrm{M} 0,78)$ & $1,2(\mathrm{M} 0,78)$ & $-14,3 \%$ & $0,9(\mathrm{M} 0,78)$ & $-35,7 \%$ \\
\hline Climb distance, FL350 [nm] & 156 & 24 & $+4,3 \%$ & 23 & $0,0 \%$ \\
\hline Take-off field length [m] & 2213 & 164 & $+5,1 \%$ & 162,5 & $+4,2 \%$ \\
\hline (FAR, MSL, ISA) & & 2129 & $-3,8 \%$ & 2197 & $-0,8 \%$ \\
\hline$v_{2}[\mathrm{~m} / \mathrm{s}]$ & 78,8 & 80,5 & $+2,2 \%$ & 80,6 & $+2,3 \%$ \\
\hline
\end{tabular}

Here, the aircraft configuration will be introduced briefly. A detailed information about the design features as well as flight performance, cost and emission calculations have been published in Weiss [5]. The reference is a short -to-medium range aircraft, similar to Boeing B737 or Airbus A320 (Figure 4 top left). The used reference engine has similar properties compared to the IAE V2500. The new short/medium range aircraft is characterized by two jet engines embedded fully into the rear part of the fuselage (Figure 4 top right). Thus, the configuration is named Rear Mounted Propulsion Aircraft (RMP). Both turbofan engines are provided with air through two long S bended ducts. Besides its primary function as intake (reducing the air velocity efficiently), the ducts are equipped with sound absorbing liner materials for attenuating the forward emitted noise, especially from the fan and compressor. In order to control the jet noise, an ejector has been installed, movable in order to optimize its efficiency as function of flight phase. The aircraft was designed with back (RMP-DT) and forward (RMP-V) swept wings. Due to the integration of the turbofans and S-ducts, the cabin has been configured with a dead end zone: reducing passenger comfort at the rear part, complicating evacuation/ de-boarding procedures as well as serviceability. Additionally, the decreased engines' accessibility and the higher load of the turbo machinery worsen its maintainability. Several aspects have been disregarded in the detailed inventory analysis due to lack of information, but peripherally considered with sensitivity studies. The calculations are principally focused on fuel burn, emissions (pollutant / noise), and seatkilometres specified direct operating cost at one operation point (range at max payload $\rightarrow$ Table 4). For better understanding a generic cabin comfort index (e.g. accounting cabin noise, space, and accessibility) was considered.

In a standard operation mode (no night time extension due to low noise operations), the novel configurations show a worse socio-eco-efficiency (Table 6: top) compared to the reference aircraft when considering all criteria listed in Table 5. The deteriorated engine efficiency and the higher aircraft weight can be indentified as the main reasons. The lower noise level of the RMP does not compensate the other disadvantages (e.g. higher fuel consumption, higher emission, and higher cost). In the present configuration, only extending the aircraft operation time into the night (by definition between 10.00pm and $06.00 \mathrm{am}$ ) improves the socio-eco-efficiency of the new aircraft (Table 6 below), because a higher utilization reduces the specific DOC (economic) and demands an additional crew (social: $\rightarrow$ higher number of employees). 
Table 5: Preliminary inventory / impact results (standard mission) [5]

\begin{tabular}{|c|c|c|c|c|}
\hline Noise & Flyover take-off & \multicolumn{2}{|c|}{ Flyover approach } & Side-Line \\
\hline Reference & $85 \mathrm{EPNdB}$ & \multicolumn{2}{|c|}{$95 \mathrm{EPNdB}$} & $93 \mathrm{EPNdB}$ \\
\hline$R M P-D T$ & $-\Delta 6,6 \mathrm{EPNdB}$ & \multicolumn{2}{|c|}{$-\Delta 8,7 \mathrm{EPNdB}$} & $-\Delta 6,5 \mathrm{EPNdB}$ \\
\hline$R M P-V$ & $-\Delta 6,8 \mathrm{EPNdB}$ & \multicolumn{2}{|c|}{$-\Delta 9,1 \mathrm{EPNdB}$} & $-\Delta 6,5$ EPNdB \\
\hline Emission, operation *) & \multicolumn{2}{|c|}{ GWP [CO2-equiv. kg] / flight } & \multicolumn{2}{|c|}{ AP [SO2-equiv. kg] / flight } \\
\hline Reference & \multicolumn{2}{|c|}{42825} & \multicolumn{2}{|c|}{10,3} \\
\hline$R M P-D T$ & \multicolumn{2}{|c|}{$47154(+10,1 \%)$} & \multicolumn{2}{|r|}{11,2} \\
\hline$R M P-V$ & \multicolumn{2}{|c|}{$49124(+14,7 \%)$} & \multicolumn{2}{|r|}{11,6} \\
\hline Emission, fuel production **) & \multicolumn{2}{|c|}{ GWP [CO2-equiv. kg] / flight } & \multicolumn{2}{|c|}{ AP [SO2-equiv. kg] / flight } \\
\hline Reference & \multicolumn{2}{|c|}{7108} & \multicolumn{2}{|c|}{28} \\
\hline$R M P-D T$ & \multicolumn{2}{|l|}{7729} & \multicolumn{2}{|r|}{30} \\
\hline$R M P-V$ & \multicolumn{2}{|l|}{8005} & \multicolumn{2}{|r|}{31} \\
\hline Emission, manufacturing $* * *)$ & \multicolumn{2}{|c|}{ GWP [CO2-equiv. kg] / aircraft } & \multicolumn{2}{|c|}{ AP [SO2-equiv. kg] / aircraft } \\
\hline Reference & \multicolumn{2}{|l|}{240000} & \multicolumn{2}{|r|}{530} \\
\hline$R M P-D T$ & \multicolumn{2}{|c|}{270000} & \multicolumn{2}{|r|}{590} \\
\hline$R M P-V$ & \multicolumn{2}{|c|}{280000} & \multicolumn{2}{|r|}{600} \\
\hline Additional ecology indicators & \multicolumn{2}{|c|}{ Land-use $* * * *)$} & \multicolumn{2}{|c|}{ Energy: fuel demand *),**) } \\
\hline Reference & \multicolumn{2}{|c|}{$110650 \mathrm{~m}^{2}$} & \multicolumn{2}{|r|}{$10,3 \mathrm{t}$} \\
\hline$R M P-D T$ & \multicolumn{2}{|c|}{$106450 m^{2}(-3,8 \%)$} & & $11,2 \mathrm{t}(+8,7 \%)$ \\
\hline$R M P-V$ & 10985 & $8 \%)$ & & $11,6 \mathrm{t}(+12,6 \%)$ \\
\hline Economy performance & DOC $_{\text {Sко }}[\$ /$ pa & & & per year [\$] \\
\hline Reference & 0,0431 & & & 20,7 mill. \\
\hline$R M P-D T$ & \begin{tabular}{l|l}
0,0446 & $0,0416(+50$ \\
\end{tabular} & zation) & & 21,4 mill. \\
\hline$R M P-V$ & \begin{tabular}{l|l}
$0,0450 \mid 0,0420(+50$ \\
\end{tabular} & zation) & & 21,5 mill. \\
\hline Social performance & Consumer $\rightarrow$ Cabin & rt [1] & No. of e & es (crew members) \\
\hline Reference & 1,0 & & 24 & \\
\hline$R M P-D T$ & 0,85 & & $24 /$ & tended ops: night) \\
\hline$R M P-V$ & 0,85 & & 24 & tended ops: night) \\
\hline
\end{tabular}

*) mission: max. range at max. payload/ pax (see Table 4), / **) kerosene / ***) materials only w/o assembly / ****) take-off field area only

Table 6: Socio-Eco-Efficiency of aircraft with overall equal weighting of criteria (top: standard mission, bottom: extended operation for RMP aircraft)

\begin{tabular}{|c|c|c|c|}
\hline standard operation & Reference Aircraft & RMP-DT & RMP-V \\
\hline Overall SEEindex *) & $61,4 \%$ & $45,6 \%$ & $38,6 \%$ \\
\hline Overall SEE-Rank & 1 & 2 & 3 \\
\hline use $50 \%$ night-time $* *$ ) & Reference Aircraft & RMP-DT & RMP-V \\
\hline Overall SEEindex *) & $20,4 \%$ & $87,2 \%$ & $77,1 \%$ \\
\hline Overall SEE-Rank & 3 & 1 & 2 \\
\hline
\end{tabular}

*) $100 \% \triangleq$ generated ideal solution among alternatives (TOPSIS) // **) night-time: 10.00pm - 06.00am, RMP aircraft only

In the preliminary design stage, there is often a lack of knowledge about specific weighting factors of the criteria. Therefore, a sensitivity study should be conducted in advance. Thus, for investigating the influence of different weighting factors on the overall result, the SEEtrade diagram was developed (Figure 5). SEEtrade is a compilation of the weight-dependent SEE-Indices of all examined alternatives. In SEEtrade the behaviour of the social-ecoefficiency vs. different weighting of ecological and economical or social criteria is depicted against a selected weighting ratio of performance indicators such as emissions vs. land-use or energy consumption. In Figure 5, the areas are reproduced where the overall SEEindex remains in a certain band depending on the weighting combination of the pre-selected criteria. Additionally, for each aircraft a curve has been inserted which indicates the boundary of 


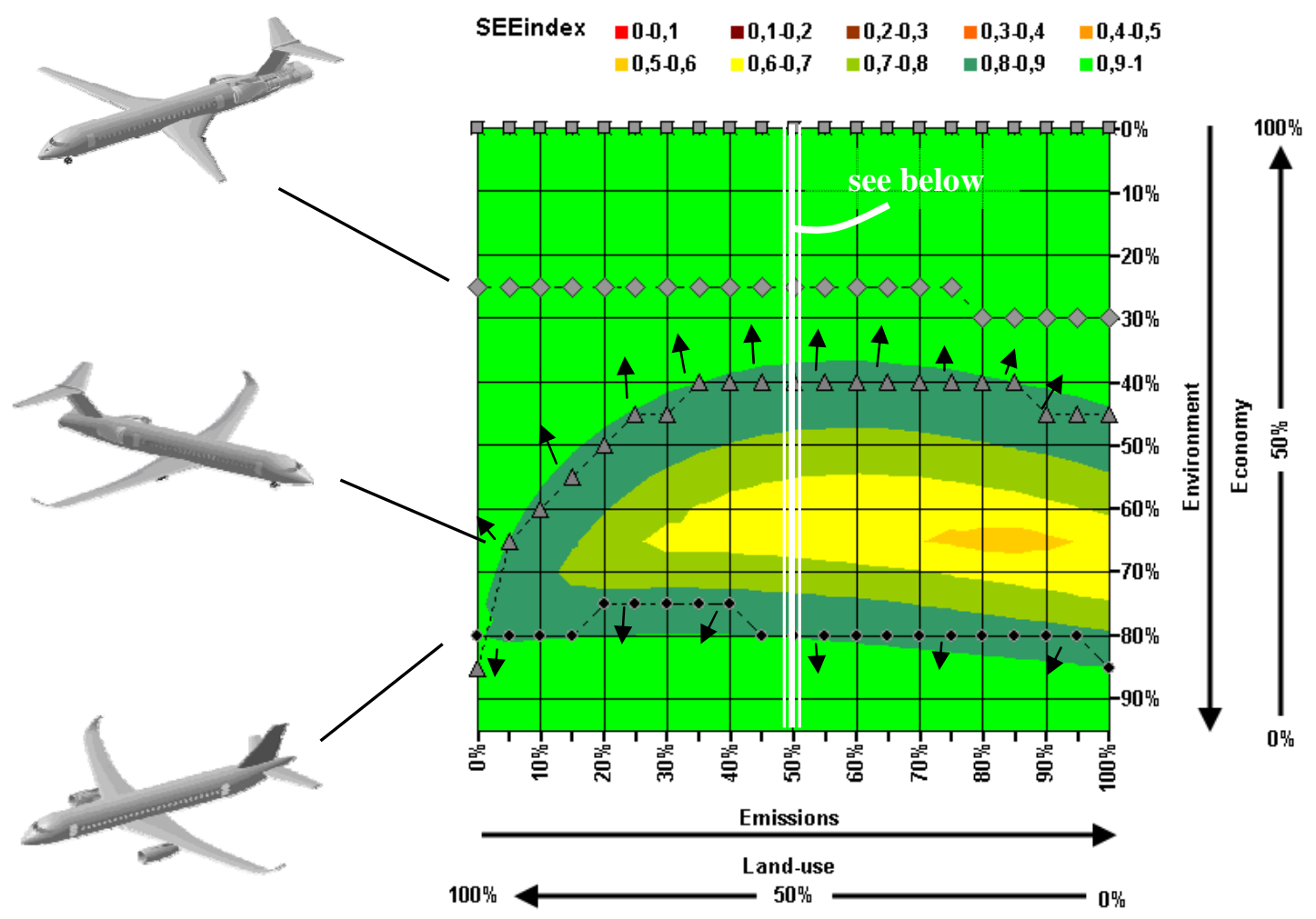

Figure 5: SEEtrade diagram (Example: Environment vs. Economy || Land-use vs. Emissions)

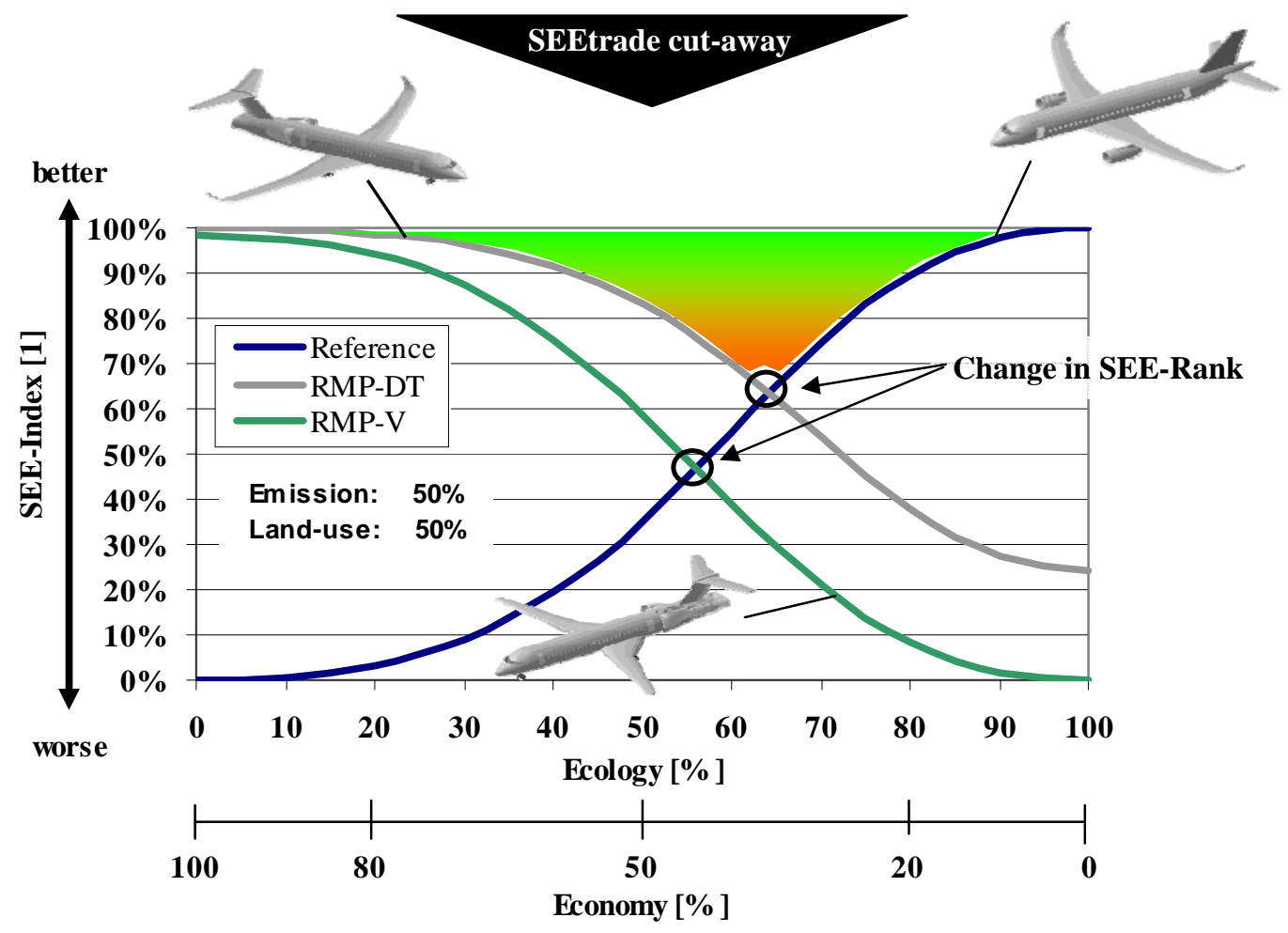

Figure 6: SEEtrade cut-away ( $\rightarrow$ compare Figure 5) 
a SEEindex up to 90\%. For example, for an environment-economy ratio of 80:20 the reference aircraft performs best against other alternatives (SEEindex $>90 \%$ ), almost independent of the weight ratio between emission and land-use. For the aircraft design alternative "RMP-DT", the SEEindex is strongly influenced by the interrelation of the weight ratios of the key performance areas (ecology vs. economy) and the performance areas (land-use vs. emissions). The higher the relevance of land-use the less important is the weighting ratio between the key performance areas economy and ecology. This is the case because of the inventory facts of an increased take-off performance, requiring less runway area ( $\rightarrow$ land-use), as well as improved overall economics ( $\rightarrow$ higher utilization).

Cutting away a specific weight ratio (e.g. land-use vs. emission $\rightarrow$ 50\%:50\%) transfers SEEtrade into Figure 6. It describes the SEEindex over the weight ratio between the key performance areas "ecology” and "economy” or "social”, keeping all remaining weighting factors constant. Therein, especially the 'switch'-ratios have to be highlighted, such as $65 \%$ ecology weight and beyond, where the reference aircraft becomes the best solution among the other design studies (although the SEEindex is around 60\%). In other words, the rank changes between the aircraft configurations (Table 7). If one gets or derives more detailed information about the criteria weights, the preprocessed results enable the user to make a decision about the configuration to be selected in order to match the future demand properly.

Table 7: Socio-Eco-Efficiency rank of aircraft at different weighting ratio between ecology and economy

\begin{tabular}{|r|c|c|c|c|}
\hline \multicolumn{5}{|c|}{ SEE-Rank } \\
\hline KPA ‘Ecology’ & $100 \%$ & $60 \%$ & $40 \%$ & $0 \%$ \\
\hline KPA ‘Economy’ & $0 \%$ & $40 \%$ & $60 \%$ & $100 \%$ \\
\hline \hline Reference & $\mathbf{1}$ & $\mathbf{2}$ & $\mathbf{3}$ & $\mathbf{3}$ \\
\hline RMP-DT & $\mathbf{2}$ & $\mathbf{1}$ & $\mathbf{1}$ & $\mathbf{1}$ \\
\hline RMP-V & $\mathbf{3}$ & $\mathbf{3}$ & $\mathbf{2}$ & $\mathbf{2}$ \\
\hline
\end{tabular}

\section{Conclusion}

For the comprehensive assessment of the Air Transportation System an approach is proposed which combines the three pillars of sustainability: Ecology - Economy - Society. For that, an index is introduced which indicates the overall performance of the investigated system in a highly aggregated number. The index is named Social-EcoEfficiency-Index or abbreviated SEEindex. The SEEindex is the final output of a multi-step procedure which starts with the inventory of the environmental, economical and social impact and is finalized with a method to synthesis all different inventory results to one number. Here, the synthesis is conducted by a MCDA process whereas TOPSIS has been recommended as the most fitting method to be applied. The calculated SEEindex is intended for both as a flexible target value to be optimized and as a fixed value to indicate the socio-eco-efficiency. Thereby it has to be differentiated between a post- and an in-loop assessment. In comparison to the post-assessment, where the alternatives have already been designed and introduced in the system, in the in-loop assessment the alternatives can be redesigned for optimizing their sustainability (SEEindex $\rightarrow$ max).

The extended assessment needs the knowledge about the relevance of the criteria to be investigated. In general the relevance is expressed as weighting factors of the performance indicators. For the case when there is a lack of knowledge of the weighting factors, a procedure is proposed to perform sensitivity studies by interrelating the weight ratios of different performance indicators. The results are visualized in a so called SEEtrade diagram. In SEEtrade the behaviour of the social-eco-efficiency vs. different weighting of ecological and economical or social criteria is depicted against a selected weighting ratio of performance indicators, e.g. as emissions vs. land-use or energy consumption. It assembles the weight-dependent SEE-Indices of all examined alternatives in one picture.

The introduced assessment process has been applied to a simplified example of low noise aircraft configurations. These are mainly characterized by fuselage embedded turbofan engines. On the one side, the integration results in a lower engine noise, on the other side, in a reduced engine efficiency ( $\rightarrow$ increased fuel consumption, air emissions). Additionally the specific direct operating costs are lower, due to an assumed higher utilization. Thus, there are more conflicting objectives to be managed in the optimization as well as decision strategy. It is shown, how the SEEindex supports the designer or evaluator in finding an optimal solution subject to certain constraints (e.g. different relevance of criteria $\rightarrow$ weights). 


\section{References}

[1] Stumpf, E. et al.; “A Methodology for Holistic Air Transport System Analysis”; German Aerospace Center, 11th ATIO conference, Virginia Beach, 2011

[2] Sun, X., Li, Y.; “An Intelligent Multi-Criteria Decision Support System for Systems Design”; 13th MAO \& 10th Aviation Technology Integration and Operation Conference, 2010.9.13-15, Texas, USA

[3] Weiss M. et al; “Applying distance-to-target weighing methodology to evaluate the environmental performance of bio-based energy, fuels and materials”; Resources, Conservation and Recycling 50, 260-281, 2007

[4] Hermann, B. et al.; “Assessing environmental performance by combining life cycle assessment, multi-criteria analysis and environmental performance indicators”; Journal of Cleaner Production 15 (2007) 1787-1796; 2007

[5] Weiss, M.; “Ein Vorschlag zur Berücksichtigung der Schallemission bei der Betriebskostenbewertung im Vorentwurf von Verkehrsflugzeugen und dessen Anwendung an einer neuartigen lärmarmen Konfiguration“; Mensch \& Buch Verlag, ISBN 9783866642911, 2007

[6] „Guidelines for Social Life Cycle Assessment of Products”; United Nations Environment Programme, 2009

[7] Henke, R. et al; "Impact of an Innovative Quiet Regional Aircraft on the Air Transportation System”; Journal of Aircraft Vol. 47, No. 3, 2010

[8] Kloepffer, W.; “Lebenszyklusbasierte Nachhaltigkeitsbewertung von Produkten”; Technikfolgenabschätzung Theorie und Praxis Nr. 3, 16. Jg., 2007

[9] Kloepffer, W; (with Comments by Helias A. Udo de Haes, p. 95) "Life Cycle Sustainability Assessment of Products”; Int J LCA 13 (2) 89-95; 2008

[10] Schaltegger, S., Sturm, A.; “Ökologische Rationalität”; Die Unternehmung Nr. 4/90, S. 273-290, 1991

[11] Seppälä, J. et al.; “On the meaning of the Distance-to-Target Weighting Method and Normalisation in Life Cycle Impact Assessment“; Int. J LCA 6(4) 211-218; 2001

[12] Finkbeiner, M.; „On the Sustainability of Eco-efficiency”; presentation at LCA VIII 2008, Seattle

[13] Finkbeiner, M. et al; “Towards Life Cycle Sustainability Assessment”; Sustainability 2010, 2(10), 3309-3322; 2010

[14] Ahlroth, S. et al.; "Weighting and valuation in selected environmental systems analysis tools - suggestions for further developments”; Journal of Cleaner Production 19 (2011), 145-156, 2011

[15] Finnveden, G. et al.; "Weighting in LCA Based on Ecotaxes- Development of a Mid-point Method and Experiences from Case Studies”; 2006

[16] Gollnick, V. et al.; "Virtual Integration Platforms (VIP) - A concept for integrated and interdisciplinary Air Transportation Concepts research and assessment”; German Aerospace Center (DLR), 11th ATIO conference, Virginia Beach, 2011

[17] 14040 International Standard 2006. Environmental management - Life Cycle Assessment - Principles and Framework, International Organisation for Standardization, Geneva, Switzerland, 2006

[18] 14044 International Standard 2006. Environmental management - Life Cycle Assessment - Requirements and Guidelines, International Organisation for Standardization, Geneva, Switzerland, 2006

[19] Saling, P. et al; “Eco-efficiency Analysis by BASF: The Method”; Int J LCA 7.4: 203-18, 2002

[20] WCED - World Commission on Environment and Development (1987): Our Common Future. Oxford 